\title{
Unipolar Reasoning in Electricity: Developing a Digital Two-Tier Diagnostic Test
}

\author{
ABDELJALIL MÉTIOUI AND LOUIS TRUDEL \\ ${ }^{1}$ Faculty of Science Education \\ Université du Québec à Montréal \\ Case postal 8888, succursale Centre-ville \\ Montréal (Québec) H3C 3P8 \\ CANADA \\ Faculty of Education \\ Université d'Ottawa \\ 75, av. Laurier Est, Ottawa ON K1N 6N5 \\ CANADA
}

\begin{abstract}
The purpose of this study was to develop a two-tier test to diagnose unipolar reasoning in electricity. Thus, at first, we built a questionnaire composed of four questions with two choices (True / False) with justification. The justification step is methodologically essential; it has allowed us to identify different categories of conceptual representations. Then we administered it to students $(N=100)$ in the Science education training program. The students' answers were analyzed and used to create the choices for the two-tier questions. The two-tier questions allow the student to give his explanation if the choices presented do not conform to his representation. Finally, high school students $(\mathrm{N}=25)$ completed an electronic version of the two-tier test to solicit their commentary. The majority was enthusiastic about their participation, despite the conceptual destabilization generated by completing this test.
\end{abstract}

Key Words: - Design, two-tier, digital version, diagnostic, alternative conceptions, electrical circuits, unipolar model

Received: November 29, 2019. Revised: May 5, 2020. Accepted: May 31, 2020. Published: June 23, 2020.

\section{Introduction}

Research conducted in numerous studies worldwide with high school and university students from established that the majority refer to erroneous conceptual models when asked to solve simple problems related to electricity and electronics compared with appropriate scientific views [1-11]. Early work by Closset and Viennot [9] identifies the use of non-scientific models by students (16-19 years old) when solving simple electrical problems. For example, in the circuit shown in figure 1, for many students, if bulbs 1, 2, and 3 are identical, they will shine with the same brightness.

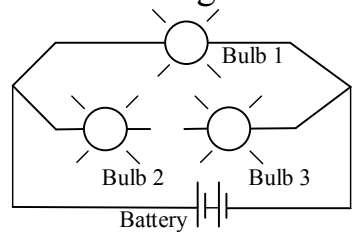

Fig. 1 The unipolar model according to Closset and Viennot [9]

These students reason that current flows from the battery to the bulb two and lit it. The return wire from this bulb to the battery seems not necessary.
This false model designated by the term unipolar model in which the current leaves from the cell (either positive or negative terminal) and arrives in the bulb and lits it was also identified among engineering students in the USA by Fredette and Lochhead [2]. Note that this unipolar model, identifying in other recent research [6-7], persists, despite formal training, only when students are asked to solve a complex circuit [7].

Regarding the conceptions of college students enrolled in "Electrical Engineering Technologies" about Ohm's law, Métioui and al. [5] have demonstrated that they faced conceptual difficulties in defining its limits of applicability.

Thus, a large proportion of the students consider all electrical and electronic systems to be linear. Therefore, faced with an unknown component in a circuit, students suppose it to be a resistance (R), which can be calculated simply by applying Ohm's law $(\mathrm{R}=\mathrm{U} / \mathrm{I})$. However, note that this alternative conception results from teaching in which we do not insist on the limits of its applicability (e.g., it does not apply to non-linear components as the transistor). 
Likewise, according to Bensghir and Closset [10], for many students, who study electricity and electrostatic, there is no potential difference between points $\mathrm{A}$ and $\mathrm{B}$, as illustrated in figure 2, since the two points have a charge of the same signs $(+,+)$.

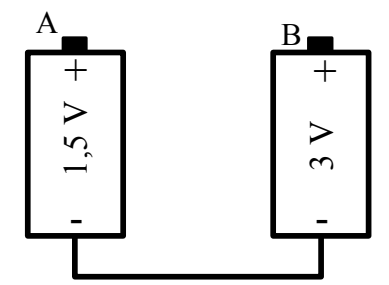

Fig. 2 Potential difference

(After Bensghir and Closset)

This false conception results from a wrong analysis of the circuit since they do not consider the fact that the batteries are not identical, and that their negative terminals are connected. Thus, points A and $\mathrm{B}$ are not at the same potential, so there is a potential difference between them.

The knowledge of alternative conceptions of college and university students is essential for delivering education that accounts for it.

On this subject, Shipstone [12] underlines in the following passage, the relevance of this problem in science education:

"The importance of this misconceptions is due both to its high incidence in the middle years of secondary school and it's to persistence among able students who have specialized in physics: it was found, for example, in seven out of eighteen graduate physicist and engineers who were training to be physics teachers." (p. 305)

Unfortunately, a great deal of research underlines the absence of teaching that accounts for the students' alternative conceptions, which are abundantly published in the Science education literature, as pointed out above.

The lack of such teaching can be explained by many factors, such as insufficient didactic formation among teachers, time constraints due to emphasis on curriculum coverage, and the large number of students in classrooms.

Consequently, more and more researchers are developing tests to quickly diagnose students' conceptions to generate interest among teachers to take into account their students' conceptual reasoning in their teaching [13-18]. On this subject, Engelhardt and Beichner [3] note below the enthusiasm aroused for this research and its relevance to detect the students' misconceptions in physics:
"Widespread use of test instruments such as the Force Concept Inventory (FCI) and the Test of Understanding Graphs in Kinematics (TUG-K) has brought a new way of evaluating students' conceptual understanding. However, more instruments need to be developed in a variety of areas to allow instructors to better evaluate their students' understanding of physics concepts and to evaluate feasibility of new teaching endeavours. In this respect, the Determining and Interpreting Resistive Electric Circuit Concepts Test (DIRECT) was developed to evaluate students' understanding of a variety of direct current (DC) resistive electric circuits concepts. DIRECT has been designed for use with high school and college/university students. Common misconceptions were incorporated into the distractors of the test items."

\section{Research goal}

The present research is in line with these works, particularly those who developed instruments for diagnosing students' basic electricity conceptions. In order to do that, we aimed to develop a two-tier test to evaluate the students' unipolar reasoning.

\section{Methodology}

The first tier of a two-tier test is a standard multiplechoice question, whereas the second two-tier encourages students to select a reason for the firsttier answer [14]. The objective of the two-tier test is to "provide researchers with the opportunity to make sense of whether a wrong answer to the first tier of an item is due to misconception or if a correct answer to the first tier means that the student understands the scientific concept." [13] To identify student reasoning, we used a qualitative methodology. In order to do that, we constructed a first-tier multiple-choice item composed of five questions. Questions were presented in the form of an item for which the students had to indicate if this one is true or false scientifically and to explain their select answer. The questions formulated do not require any recourse to mathematical formulas, so the student must argue qualitatively his answer.

\subsection{Sample and Data Collection}

One hundred students (between 20 and 25 years old) registered in the third year of university in the Baccalaureate Program in Science Education completed the questionnaire lasting sixty minutes. These students took a course in electricity during their secondary studies. Also, as part of a university course, they received two periods of training, each one of three hours duration, in the study of simple 
electrical circuits in a laboratory context. Secondly, from the analysis of the students' answers to the questionnaire, we developed a two-tier digital test to diagnose the students' reasoning about electrical circuits rapidly.

\subsection{First-tier questionnaire Design: Students' alternative conceptions}

We have retained five questions to identify students' alternative conceptions about their behavior relative to the functionality of an open and closed circuit. It should be noticed that these questions considered the researchers previously highlighted. Herewith are the target objectives put forth by each of the questions.

\subsubsection{First question}

The objective of the first question illustrated in figure 3 is to verify if, for the student, there is an electric current in the wires going to the bulb while its filament is broke. Hence, the circuit in which the bulb is connected is open.

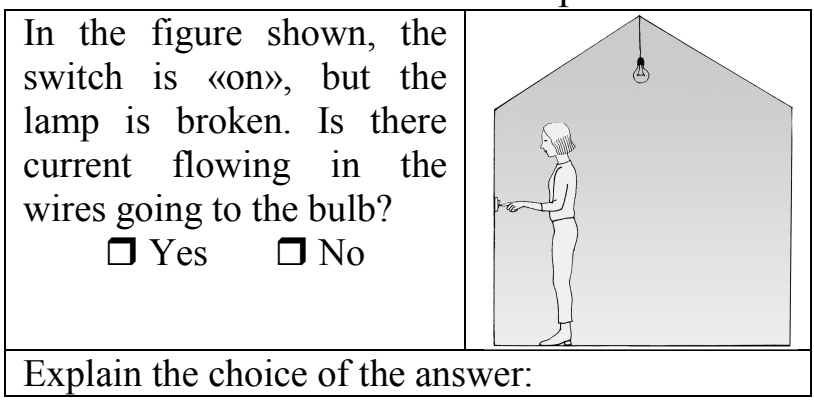

Fig. 3 Paper-questionnaire: Question \#1

\subsubsection{Second question}

The objective of the second question illustrated in Figure 4 is to verify that, for the student, the branch containing bulbs $\mathrm{B}$ and $\mathrm{C}$ is open; therefore, these bulbs will not work. As for bulb A, this depends on its operating characteristics and the battery voltage.

The bulbs A, B, and $\mathrm{C}$ in the circuit shown are identical

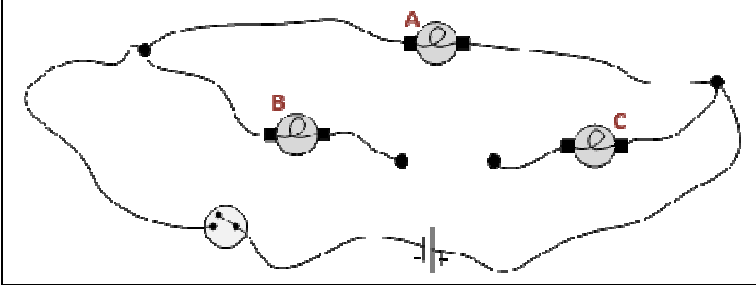

Is the statement below true or false?

"The three bulbs will light up with the same brightness when the switch is closed."

\begin{tabular}{|c|c|}
\hline$\square$ Yes & $\square$ No \\
\hline Explain the choice of the answer: \\
\hline
\end{tabular}

Fig. 4 Paper-questionnaire: Question \#2

\subsubsection{Third question}

The objective of the third question illustrated in figure 5 is to verify if, for the student, the fact that if the bulb A works, then bulb B cannot be burnt since it is connecting in series with bulb A. Indeed, it does not light because its current and voltage characteristics are different compared to bulb A.

In the diagram shown, the bulb A lights normally, while bulb $\mathrm{B}$ does not light. Is the following statement true or false? "Bulb B does not light because its burned."

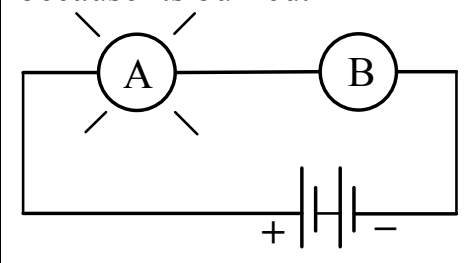

$\square$ True
$\square$ False
Explain the
choice of the
answer:

Fig. 5 Paper-questionnaire: Question \#3

\subsubsection{Fourth question}

The objective of the fourth question illustrated in figure 6 is to verify if, for the students, the bulb B cannot work because its circuit is open. Moreover, if we connect a wire between the $(+)$ and (-) terminals of the two batteries to close the circuit, bulb B burns if bulb A works because the voltage across its terminals is $3 \mathrm{~V}$.

In circuits 1 and 2 below, lamps $\mathrm{A}$ and $\mathrm{B}$ are identical, as are the two batteries.

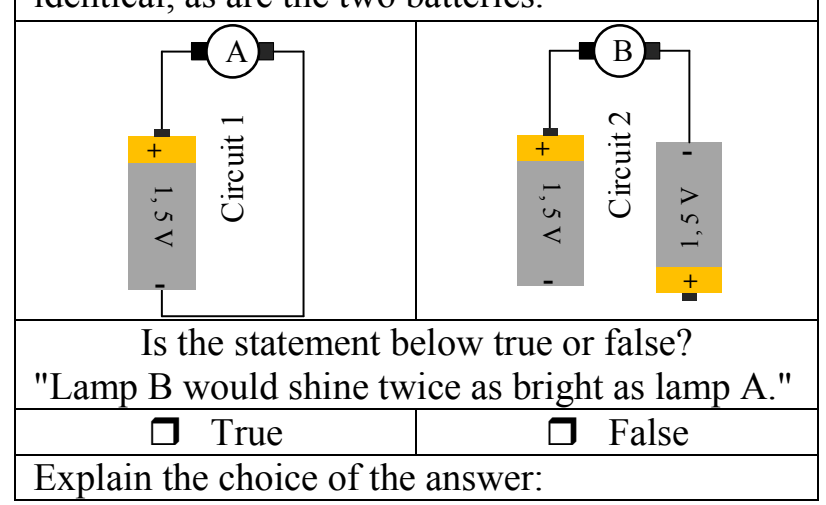

Fig. 6 Paper-questionnaire: Question \#4

\subsubsection{Fifth question}

The circuit below is like circuit 2 (Question 4). The lamp could not light because of the open circuit, and if we close it, bulb B burns because the voltage across its terminals is $12 \mathrm{~V}$.

In the circuit shown, the lamp will normally light with $6 \mathrm{~V}$.

Is the affirmation below true or false?

"The lamp will light normally since the electric current moves from the pole + to the pole -."

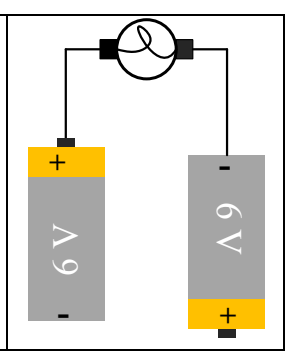




\begin{tabular}{|c|c|}
\hline$\square$ True & $\square$ False \\
\hline Explain the choice of the answer: \\
\end{tabular}

Fig. 7 Paper-questionnaire: Question \#5

\subsection{Analysis of Data}

First, we compiled the responses, one question at a time, each taken separately. For each of them, we proceeded to group the answers into different categories, the number varying from one item to another, depending on the different responses obtained. Note that the analysis of the responses started with the distinction between good and wrong answers and incomplete or indecipherable answers. To qualify students' explanations as right or incorrect, we compare them to the solutions presented above (section 3). Secondly, we interpreted all the responses identified in the selected categories to synthesize the most common errors.

\subsubsection{Analysis of the first question}

The explanations gave by the students enabled us to note for their majority the absence of the correct scientific representation about the open and closed circuit. We have identified three conceptual categories representations presented below. Some students' justification is given in Table 1.

Table 1: Categorization and students' responses to question \#1

\section{Category 1: 16/100-16\%}

No current flows in the wires because the circuit is open.

"The current must leave from one point and come back to the same point. In this case, the current cannot complete the circuit because of the burned filament of that lamp." (S49)

"To say that there is an electric current in a circuit, the current should flow throughout the circuit at one point and come back to it. However, since the circuit is open, there is no flow of current." $\left(\mathrm{S}_{69}\right)$

$$
\text { Category 2: } 52 / 100-52 \%
$$

The switch is "on"; therefore, the currents flow in the wires leading to the bulb.

"There is a flow in the electric wires because the switch is On, even if the bulb is burned." (S3)

"If you replace the bulb with a new one, the new bulb will light without changing the position of the switch." $\left(\mathrm{S}_{79}\right)$

$$
\text { Category 3: 20/100-20\% }
$$

The lamp does not light because its filament is broken. Despite this fact, the electrical current continues to flow through the bulb.
"The fact that the bulb does not work is referred solely to the burned filament. The switch is "On", and the current continues to flow." $\left(\mathrm{S}_{54}\right)$

In the end, 12 students advanced unreadable explanations, and therefore, we were unable to identify their conceptions.

\subsubsection{Analysis of the second question}

We have identified five conceptual categories following the analysis of the students' explanations presented in Table 2.

Table 2: Categorization and students' responses to question \#2

\section{Category 1: 20/100-20\%}

The bulbs $\mathrm{B}$ and $\mathrm{C}$ will not light because the branch in which they are is open.

"Only bulb A will shine because it is the only that makes the closed circuit." $\left(\mathrm{S}_{48}\right)$

"Only bulb A will shine because it is the only one that is part of a complete electric circuit." $\left(\mathrm{S}_{63}\right)$

$$
\text { Category 2: 13/100-13\% }
$$

Bulb A will shine with more brightness than bulbs $\mathrm{B}$ and $\mathrm{C}$ because it connects to the two terminals of the battery.

"Bulb $A$ is going to shine with more brightness because it is connected by one wire that carries the total current from the battery. In the case of bulbs $B$ and $C$, the electric current is carrying by two wires; therefore, they are dimmer." $\left(\mathrm{S}_{65}\right)$ "Bulb will light brighter since it is connected from two points by an electric wire that carries the current, whereas bulbs $B$ and $C$ have less current because the wires are not connected." $\left(\mathrm{S}_{84}\right)$

$$
\text { Category 3: 10/100-10\% }
$$

Bulb A will shine less than bulbs $\mathrm{B}$ and $\mathrm{C}$ because it is far away from the battery.

"Bulbs $B$ and $C$ will be brighter than bulb $A$ because the electric current will reach them first." $\left(\mathrm{S}_{20}\right)$

Category 4: 12/100-12\%

Bulb $\mathrm{C}$ will light less than bulbs $\mathrm{A}$ and $\mathrm{B}$ because the current leaving the battery is divided between bulbs $\mathrm{A}$ and $\mathrm{B}$, and the current flow through bulb A will cross bulb C.

"It would be necessary to determine the positive and negative terminals of the battery. If the negative pole is on the left, bulbs $A$ and $B$ will shine brighter than bulb C." (S5)

\section{Category 5: 8/100-8 \%}

Bulb C brights less than A and B because of a parallel circuit. 
"Bulb C will be dimmer since it is connecting in a parallel circuit. The current will divide between bulbs $A$ and $B$, and the remaining current of bulb A will separate before going toward bulb C." $\left(\mathrm{S}_{27}\right)$

In category 1 , no student specified the bulb (A) characteristics for it working compared to those of the battery.

\subsubsection{Analysis of the third question}

We have identified five categories following the analysis of data presented in Table 3.

Table 3: Categorization and students' responses to question \#3

Category $1: 20 / 100-20 \%$

The bulb B cannot be burnt. Otherwise, the circuit would be open.

"The circuit is functioning; electricity must flow throughout the circuit; therefore, bulb B cannot be burning." (S19)

"In this case, if bulb B is burned, bulb A would not light. However, if the two bulbs are connected in parallel, and bulb B is burned, bulb A would not be affected and remains lighted." (S64)

$$
\text { Category 2: 20/100-20\% }
$$

If bulb B does not light, then it is burned.

"The current should flow, therefore if it is not illuminated, that is that it burnt out." $\left(\mathrm{S}_{1}\right)$

$$
\text { Category } 3: 30 / 100-30 \%
$$

Bulbs B does not light because bulb A used all the current (or energy) of the battery.

"Perhaps bulb A used up the total current, and there is no current left to light bulb B." $\left(\mathrm{S}_{6}\right)$

"Either bulb B is burned, or bulb A has used the whole current to remain lighted." $\left(\mathrm{S}_{35}\right)$

"Perhaps the battery is down because it has used all of its energy to light bulb A. Therefore, the battery could not supply bulb $B$ with enough energy. If bulb $B$ is burned, the whole circuit will not work." $\left(\mathrm{S}_{40}\right)$

$$
\text { Category } 4: 24 / 100-24 \%
$$

Bulb A receives much electrical current from the positive terminal compared to bulb A who receives less electrical current from the negative terminal, which is why it does not lit.

"Because the negative side of the battery has as much current as the positive side." $\left(\mathrm{S}_{68}\right)$

Because the positive side of the battery is more robust than the negative terminal." $\left(\mathrm{S}_{99}\right)$

Category $5: 6 / 100-6 \%$

Bulb B does not light because it is badly screwed.

"Bulb B is not necessary burned. It might have a poor connection." $\left(\mathrm{S}_{86}\right)$

Students in category 3, considering that two bulbs in series, the lamp placed near the positive terminal of the battery receives the current necessary for its lightning. The second bulb does not light because the first bulb used the total current. It is about the attenuation model identified by many researchers.

\subsubsection{Analysis of the fourth question}

We have identified six categories following the analysis of the students' explanations presented in Table 4.

Table 4: Categorization and students' responses to question \#4

Category $1: 22 / 100-31 \%$

Circuit 2 is open; then, bulb B will not lit.

"Bulb A will light, whereas bulb $B$ will not because the current does not flow beyond the positive terminal of the second battery." $\left(\mathrm{S}_{1}\right)$

"So that the bulb lights, the energy must come out of (+) and (-) terminals of the same battery; otherwise, the bulb B won't light because there is no energy dissipation." $\left(\mathrm{S}_{8}\right)$

$$
\text { Category } 2: 15 / 100-15 \%
$$

Bulbs B will light similarly to bulb A because their wires are connecting the positive terminal to the negative terminal of the second battery.

"Bulbs $A$ and $B$ should shine the same way since each one has a positive and negative terminal." $\left(\mathrm{S}_{12}\right)$

\section{Category 3: $8 / 100-8 \%$}

Bulbs A and B will light similarly because the batteries are identical.

"The $B$ bulb shines as the bulb $A$ because it leaves the positive in $1,5 \mathrm{~V}$ and arrives at the negative in 1,5 $V$." $\left(\mathrm{S}_{9}\right)$

"Considering that the two batteries are identical,

I think bulbs $A$ and $B$ will shine similar." $\left(\mathrm{S}_{11}\right)$

$$
\text { Category 4: 20/100-20\% }
$$

Bulb B will light more than bulb A because it receives more current than lamp B.

"In circuit 1, there is only one pole + to provide the current. In-circuit 2, there are two poles + to provide the current. Therefore this circuit offers more electric current." $\left(\mathrm{S}_{70}\right)$

Category 5: 20/100-26\%

Bulb B will light more than bulb A because it receives more voltage $(3 \mathrm{~V})$.

"Bulb $B$ will shine more strongly since it is connected to 3 volts rather than 1,5 V." $\left(\mathrm{S}_{26}\right)$ Category 6: 15/100-26\% 
The lighting of the lamp of circuit 2 will be more extended because of the two batteries.

"If the two bulbs are identical, lit once, they will remain identical. Only the bulb $B$ will light more." (S81)

\subsubsection{Analysis of the fifth question}

We have identified five categories following the analysis of the advanced explanations presented in Table 5.

Table 5: Categorization and students' responses to question \#5

\section{Category $1: 36 / 100-30 \%$}

The circuit is open. It would be necessary to join the two other poles of the two batteries by a wire so that the current circulates.

"It is necessary to connect the two batteries with a wire to form a complete circuit." $\left(\mathrm{S}_{7}\right)$

"The electric current flows from (+) to (-) when it reaches only one battery." $\left(\mathrm{S}_{10}\right)$

"No lighting because the batteries are not properly connected. No reaction in solutions to cause electrical energy." $\left(\mathrm{S}_{33}\right)$

Category $2: 28 / 100-42 \%$

The bulb is connecting to the positive pole of a battery and the negative pole of another, then it works.

"It will normally shine because it is plugged in the positive and the negative terminals." $\left(\mathrm{S}_{47}\right)$

"According to the convention, the current leaves the battery and goes from the positive side to the negative." $\left(\mathrm{S}_{55}\right)$

"The electric current should flow between the positive and the negative." $\left(\mathrm{S}_{65}\right)$ Category $3: 36 / 100-28 \%$

The lamp will light because the two batteries have the same voltage $(6 \mathrm{~V})$.

"This is true because the two batteries used are identical, they have the same voltage $(6 \mathrm{~V}) . "\left(\mathrm{~S}_{22}\right)$

In category 1 , only one student has specified that the bulb will not light up even if the circuit is closed because of the voltage:

"This circuit is not closed. The two batteries are not connected. The negative pole of bulb A must touch the positive pole of 2. The bulb must also support a voltage of $12 \mathrm{~V}$ (the lamp will not light)." $\left(\mathrm{S}_{22}\right)$

\section{Two-tier diagnostic test design}

For each question, we retained four or five categories, including the scientific answers. Thus, we have eliminated those that are indecipherable, off-topic, or incomplete. In Annex, we will present the two-tier test constructed with these categories.

A digital version of the two-tier test was administered to a sample of 25 volunteer high school students at the start of their electricity lessons. These students had taken a course in electrical circuits during their high school studies. In the end, we asked them to give us their commentary on the test (see Appendix).

They liked to complete the questionnaire electronically despite a frustration felt. Indeed, many were destabilized by trying to solve problems qualitatively. In general, they calculate current and voltage from Ohm's and Kirchhoff's laws.

Besides, they found that the explanations they proposed to justify their choice of answer raised doubts concerning their previous knowledge, and thus they felt destabilized. They also really liked to receive by email the digital version of the questionnaire to fill it out and return it to us electronically. This way of proceeding, among other things, solve the constraint related to time teaching highlighted in the introduction.

\section{Conclusion and Limite of the study}

In conclusion, the analyzes of the paper-pencil questionnaire revealed the difficulty of students' qualitative understanding of simple electric circuits. McDermott and Finely [19] underlined in the following passage, the students' conceptual difficulty to solve qualitative problems on electrical circuits:

"It is becoming increasingly apparent that success in solving quantitative problems is not a reliable measure of conceptual understanding. Instructors at high school and university levels corroborate our experience that students who can solve standard quantitative problems often cannot answer simple qualitative questions based on the same physical concepts." (page 995).

We also showed the existence of multiple contradictory conceptual representations constructed by a student of the same physical concept (e.g., current, voltage, energy), as illustrated in the students' explanations.

Regarding this phenomenon, researchers identified multiple representations in the development of students' cognitive structures [20].

Finally, we developed second-tier questions thanks to the representations of the students identified in analyzing each item of the first-tier questionnaire with justification. 
Unfortunately, the test developed does not cover the study of complex circuits to analyze students' unipolar reasoning.

Also, it should be tested with students to assess its impact on unipolar reasoning. There is a need for such research.

Despite these limits, the two-tier diagnostic test developed can be used as an instrument for educators to gain a correct vision of student reasoning about the unipolar reasoning before teaching.

References:

[1] Arnold, M., and Millar, R, Being constructive: An alternative approach to the teaching of introductory ideas in electricity, International Journal of Science Education, Vol. 9, No. 5, 1987, pp. 553-563.

[2] Fredette, N., and Lochhead, J, Student conceptions of simple circuits. Physics Teacher, Vol. 18, No 3, 1980, pp. 194-198.

[3] Engelhardt, P. V. and Beichner, R. J, Students' understanding of direct current resistive electrical circuits. American Journal of Physics, J. Phys., Vol. 72, No 1, 2004, pp. 98-115.

[4] Métioui, A., and Trudel, L, The notion of modeling among the students of technical college (pp. 1-13). Proceedings of the ESERA 2013 Conference, Constantinou, C. P., Papadouris, N., \& Hadjigeorgiou, A. (Eds.), 2014.

[5] Métioui, A., Brassard, C., Levasseur, J., and Lavoie, M, The persistence of students' unfounded beliefs about electrical circuits: the case of Ohm's law, International Journal of Science Education, Vol. 18, No 2, 1996, pp. 193-212.

[6] Mackay. J., and Hobden, P, Using circuit and wiring diagrams to identify students' preconceived ideas about basic electric circuits, African Journal of Research in MST Education, Vol. 16, No 2, 2012, pp. 131-144.

[7] Métioui, A., \& Trudel, L, The persistence of the alternative conceptions: The case of the unipolar model (pp. 117-127). Proceeding of the GIREP-MPTL, C. Fazio and R.M. Sperandeo Mineo (Eds.), University of Palermo, Italy, 2014.

[8] Métioui, A., and Trudel, L, Secondary Students' Conceptions after Teaching: The Case of the Physical Properties of the NonBiased Diode, Academic Journal of Science, Vol. 4, No 2, 2015, pp. 143-154.
[9] Closset, J. L., and Viennot, L, Contribution à l'étude du raisonnement naturel en physique, Communication Information, Vol. 6, No 2-3, 1984, pp. 399-420.

[10] Bensghier, A., and Closset, J. L, Prégnance de l'explication électrostatique dans la construction du concept de circuit électrique: points de vue historique et didactique, Didaskalia, No2, pp. 31-47, 1993.

[11] Dupin, J. J., and Johsua, S, Conceptions of French pupils concerning electric circuits: Structure and evolution, Journal of Research in Science Teaching, Vol. 29, No 9, 1987, pp. 791-806.

[12] Shipstone, D, Pupils understanding of simple electrical circuits, Physics Education, Vol. 23, 1988, pp. 92-96.

[13] Peşman, H., and Eryılmaz, A, Development of a Three-Tier Test to Assess Misconceptions About Simple Electric Circuits, The Journal of Educational Research, Vol. 103, pp. 208-222, 2010.

[14] Treagust, D. F, Development and use of diagnostic tests to evaluate students' misconceptions in science, International Journal of Science Education, Vol. 10, No. 2, 1988, pp. 159-169.

[15] Urban, H, Sequential Reasoning in Electricity: Developing and Using a Three-Tier Multiple Choice Test. Scientia in educatione, Vol. 8 (Special Issue), 2017, pp. 285-292.

[16] Métioui, A, Constructing a Two-Tier Test about Source Current to Diagnose Pre-Service Elementary School Teacher's Misconceptions. International Journal of Educational and Pedagogical Sciences, Vol. 13, No 3, 2019, pp. 345-349.

[17] Coppens, N., and Munier, V, Monitoring Student Progress in Physics Using Double Multiple-Choice Questions, Didaskalia, Vol. 27, 2005, pp. 41-64.

[18] Hermita, $\mathrm{N}$ et al., Constructing and Implementing a Four Tier Test about Static Electricity to Diagnose Pre-service Elementary School Teachers' Misconceptions, Journal of Physics Conference Series, 2017, 895012167.

[19] McDermott, L. C., and Finely, F. N, Research as a guide for curriculum development: An 
example from introductory electricity. Part I:

investigation of student understanding.

American Journal of Physics, Vol. 60, No 11, pp. 994-1003.

[20] Baptista, M., Martins, I., Conceição, T and Pedro Reis, P. (2019). Multiple representations in the development of students' cognitive structures about the saponification reaction. Chem. Educ. Res. Pract., 20, pp. 760-771.

\section{Appendix \\ Two-Tier Diagnostic Test: Unipolar reasoning}

\section{Question \#1}

In the figure shown, the switch is «on», but the lamp is burnt out (broken).

In your opinion, is there current flowing in the wires going to the bulb:

$$
\square \text { Yes } \square \text { No }
$$

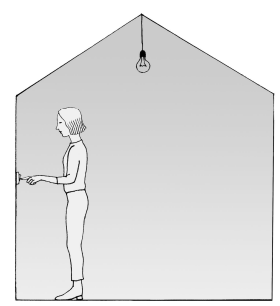

Which of the following explanations best justifies your answer?

$\square$ There is current that reaches the lamp wire but does not flow through it. The current cannot get through at this point because the filament of the lamp is broken.

$\square$ The current always flows through the wires leading to the bulb, but since the filament is burnt out, the bulb will not light up. If you replaced the burnt-out bulb with a new one, the new one will light up without changing the position of the switch, which confirms that the current was circulating.

$\square$ The current does not circulate because the circuit is open because the filament of the bulb is broken.

$\square$ The current is always flowing since it is the switch that determines the electric current supply to the lamp.

\section{Question \#2}

The bulbs A, B, and C in the circuit below, are identical, do you think they will light up with the same brightness when the switch is closed?

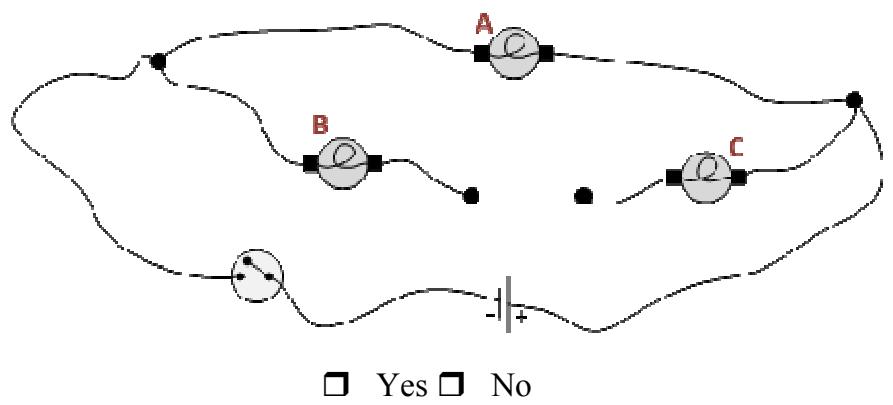

Which of the following explanations best justifies your answer?

$\square$ The bulbs will light up with the same intensity because the electric current will be uniformly shared between the three bulbs, because they are identical.

$\square$ The bulbs will not light up with the same intensity because the current comes out first from the + terminal of the battery so, bulb B will be less bright.

$\square$ The lamp A will only light up if the voltage of the battery is appropriate for the lamp's operation. As for bulbs B and C, they will not work because that branch of the circuit in which they are connected is left open.

$\square$ The bulbs will all light up with the same intensity because they will get power at the same time. That is to say; they will all be the first on the flow of the electric current coming from the battery. 


\section{Question \#3}

In the diagram shown, the bulb A lights normally, while bulb B does not light.

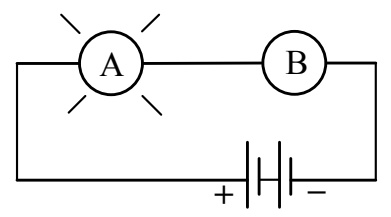

In your opinion, is the following statement true or false: "If bulb B does not light up it is because it is burned out."

$$
\square \text { True } \square \text { False }
$$

Which of the following explanations best justifies your answer?

$\square$ The current goes from the (+) terminal to the bulb A; it means that on its way, the flow also passed bulb B, and it does not lit. So, it either it is burnt or wrongly connected because the flow did go through it.

$\square$ Even if bulb B is burned out, it can act as a conducting wire. That's why bulb A is lit.

$\square$ Bulb B cannot be burned out because the circuit would be open and bulb A will not light.

$\square$ In a series circuit, if a bulb were no longer functional, the circuit would no longer be closed. In this case, the circuit would be open, and the set of lights would no longer light up. Therefore, it is impossible for a single bulb in the circuit not to light, because if necessary, the circuit would be open, and the other lamp would not light either.

\section{Question \#4}

In circuits 1 and 2 below, lamps $\mathrm{A}$ and $\mathrm{B}$ are identical as are the two batteries. In your opinion, is the following statement true or false: "Lamp B would shine twice as bright as lamp A."
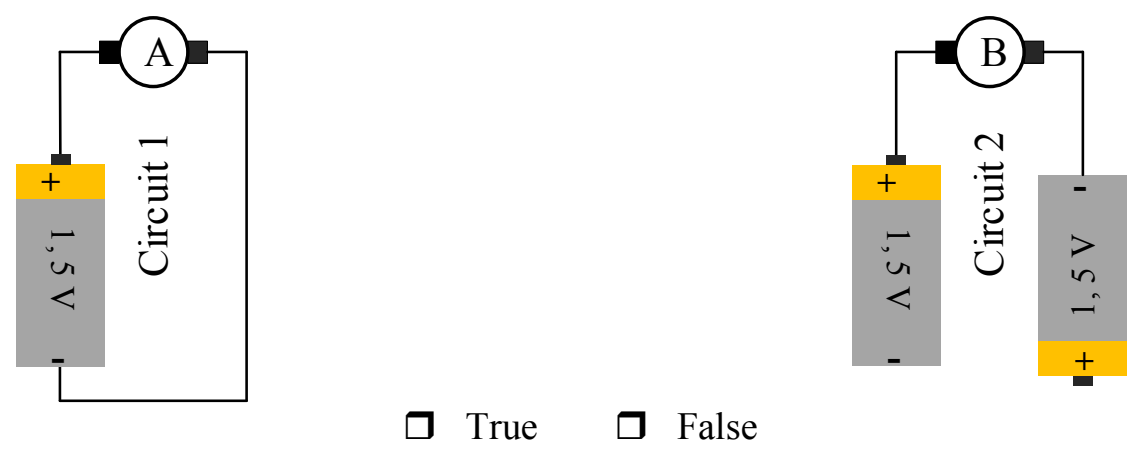

Which of the following explanations best justifies your answer?

The lamp B will not shine twice as bright than lamp A. The lamps will shine equally since they are both connected to a circuit that starts from terminals $(+)$ to $(-)$.

$\square$ They will have the same brightness, because the two batteries in circuit 2 are not connected by a wire, so that the current is not doubled.

$\square$ The bulb B will not light because the wire between the two batteries is cut so its circuit is open.

$\square$ The bulb B will shine twice as bright as bulb A. The higher the number of volts, the stronger the current will be, and the more the bulb will ignite. The bulb (A) has only $1.5 \mathrm{~V}$ while bulb (B) has double. 


\section{Question \#5}

In the circuit shown, the lamp will normally light with $6 \mathrm{~V}$-Battery.

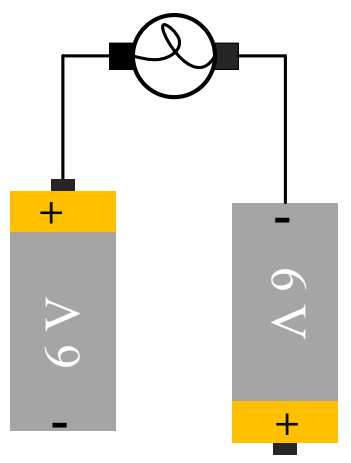

Is the affirmation below true or false?

"The lap will light since the electric current flows across its poles plus (+) and mines (-) terminals."

$$
\square \text { Yes } \square \text { No }
$$

Which of the following explanations best justifies your answer?

$\square$ The lamp will light up because the electric difference in electrical potential across its terminals is equal to $6 \mathrm{~V}$.

$\square$ The lamp will not light because the circuit is open. For it to light up, we must connect a wire between the two + and - terminals of the two batteries to close the circuit.

$\square$ For the lamp to work, the circuit must be close. However, if we close the circuit it will burns because the voltage across it will be $12 \mathrm{~V}$.

$\square$ The lamp will light because the current is moving from the positive pole of one battery to the negative pole of the second battery.

$\square$ The lamp will not light because the voltage at its terminals is $12 \mathrm{~V}$. 